\title{
A Study on Safety Regains of BRTS Corridor Intersection
}

\author{
Vipul Vikram Mathur, Anirudh Mathur, Nishant Sachdeva \\ Department of Civil Engineering, Swami Keshvanand Institute of Technology, Management \& Gramothan, Jaipur- \\ 302017 (INDIA) \\ Email: vipulvmathur@gmail.com, anirudh.mathur@skit.ac.in, nishant.sachdeva@skit.ac.in \\ Received 22.07.2021, received in revised form 8.08.2021, accepted 9.08.2021 \\ doi: $10.47904 / I J S K I T .11 .2 .2021 .1-4$
}

\begin{abstract}
The development of Public Transportation Infrastructure needs utmost attention to solve the issues related to congestion, accidents, and pollution. Bus Rapid Transit System (BRTS) has turned out to be one the effective and safe mode. For smooth functioning of the same, all the infrastructure elements linked to the corridor must also be designed accordingly. The current study focuses on redesign of an intersection of BRT Phase-II corridor in Jaipur city. The deficiency in the existing design related to geometrics, traffic control features etc. were examined. The redesign of the selected intersection has been presented showcasing the safety gains.
\end{abstract}

Keywords- Public Transportation Infrastructure, Intersection, Safety Gains.

\section{INTRODUCTION}

Due to rapid industrialisation, economic growth and better job opportunities, the Urban Agglomerations in India are witnessing substantialexodus of population from rural areas. During 1951 to 2001, an increase in the population from $17.3 \%$ to $27.8 \%$, which presently stands at $35 \%$ and likely to be $45 \%$ by year 2030 [1]. In comparison to the population CAGR of $2.1 \%$, the passenger KM travel increased at $9.4 \%$ CAGR during the half century [2]. Due to increase in the vehicle ownership, issues like congestion, travel delay, environmental degradation have been increased. This sudden explosion in urban population has put enormous burden on the existing infrastructure and drawn the attention of the governments and transport planners to provide various solutions to ease out the traffic congestion in the UAs and provide various mass transit systems which can function speedily and concurrently.

This significant increase in urban population will increase the demand for transportation, energy, mobility, water, and other urban services in cities. So effectually, cities have to psych up for the speedy growth and become more efficient in provision of urban services.

\subsection{BRTS in India}

In India, the concept of BRTS was understood very late as compared to the rest of the world. First BRTS in India was planned and implemented in Pune in year 2006, followed by Delhi, Ahmadabad, Jaipur, Vijayawada, Rajkot, Surat, Indore and then to many other Indian cities. By far, Ahmadabad BRTS is the best BRTS in India with a global popularity and Bhopal has the largest BRTS in India [3]. Rajasthan was one of the pioneer states to implement BRTS and after implementing at Jaipur, it was proposed in Jodhpur, which was a failed project due to some local issues.

\section{REVIEW OF LITERATURE}

Many researchers in the field of transportation, urban planning and economics have carried out studies related to the selected study all over the world. Michaela Sidloski et.al (2020) [4] in their research examine comparison of BRT systems of sixteen small and average size cities with large metro cities of North America. A large amount of data was collected from various agencies with respect to the ridership, volume, frequency etc and analysed with large metro cities. It was concluded that BRT system that there is higher ridership levels and volume in larger cities as compared with smaller and mediumsized cities in North America. Vivek Patel et.al. (2020) [5] carried out analysis in Indian perspective and concluded that public transport authorities in large metro cities in India are suffering losses due to ill planned services and infrastructure. Public choice of modes also differs from city to city. There are different public transportation solutions for different cities based on geography of the city, mode choice of people, development of the city etc. The performance and selection of choice of mode depends on Peak Hour Peak Direction Traffic (PHPDT), average expenditure on public transport, length of trip, population of city and difference of cost of travel by different modes as well as affordability.

Moazzem (2006) [6] researched on the BRT as a sustainable approach and analysed those cities in developing countries in general and India are looking for sustainable solutions to their accessibility and mobility problems. The process is complicated by the rapid growth of cities known for vehicle operations, live and non-motorized transport routes, the decline of public and institutional transport services, and the deterioration of air quality. Currently, public transport is less profitable, speeds are slowing, and congestion is increasing, and traffic is a source of environmental problems. To meet these needs, BRTS is one of the best solutions to the problem 


\section{OBJECTIVES}

The objectives of the study are:

- To find out the design deficiencies of the selected stretch.

- To rectify the deficiencies and improve the geometrics of selected intersections for safe movement.

\section{SCOPE OF THE STUDY}

There is a huge scope of improvement of the existing corridor. I have done my work on finding the issues pertaining to the selected stretch, redesigning of selected intersections, and recommending measures for increasing the mobility of corridor. This paper presents a detailed study of safety audit at two junctions on a constructed BRTS corridor in Jaipur as well the likely reasons for unexpected underuse of the created infrastructure.

\section{METHODOLOGY}

BRTS corridor was selected as it is one of the key elements of urban mass transit system in Jaipur City. There are various junctions in the BRTS corridor of Jaipur city but as per the stakeholder's survey, the Bhrigu path intersection faces large traffic (motorised as well as non-motorised) movement disorders due to poor geometry at the intersection. So, the geometry at the intersection was studies by visual inspection and recommendation related to redesigning of the junction were proposed for smooth and safe movement of traffic.

\section{OBSERVATIONS DURING STUDY}

During the study, a detailed reconnaissance was carried out and the existing layout of the junction at Brigu Path was studied. Following observations were made:

- This intersection is too large.

- This is a three-legged intersection.

- Intersection is situated at a very steep / sharp curve which is a road geometrics issue.

- There is no refuge island for pedestrians to cross over.

- For fast moving buses, there is an almost blind curve.

- No route marking or guide marking was found, which can guide the driver about the sharp curve.

- No chevron signboards were found.

- Last stretch is too short for the bus to pick up speed.
- Safety Deficiencies- The safety deficiencies found at this junction are:

- The $0.5 \mathrm{~m}$ wide separator between main carriageway and BRT lanes is insufficient to accommodate pedestrian/passenger who are crossing the road

- The existing layout with wide open space without any channelizing islands will promote reckless movement.

- No provision of authorised parking along the urban road may encourage haphazard unregulated onstreet parking, which is likely to affect the capacity and safety.

- Traffic signal heads are not conspicuous enough to be seen by approaching drivers. Moreover, traffic signal system set with continuous Flashing Amber light during off-peak hours will be highly dangerous, as it serves no control.

- The opening/access of the minor street opposite to Bhrigu Path very near to junction has increased the number of conflicts.

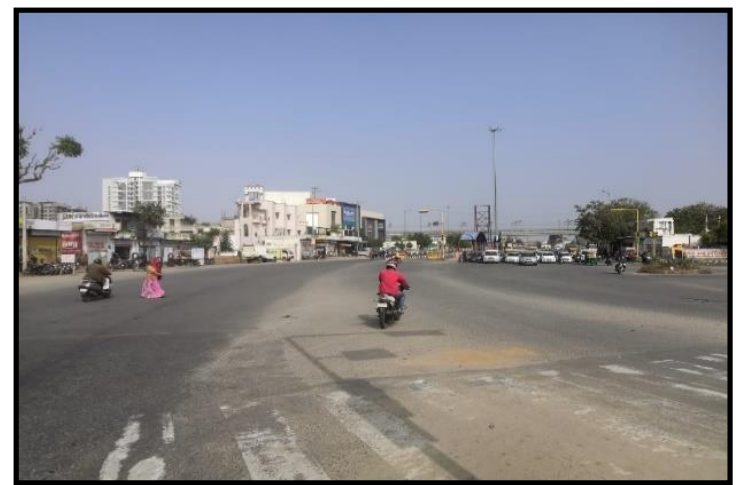

Fig. 1 Intersection size is too wide

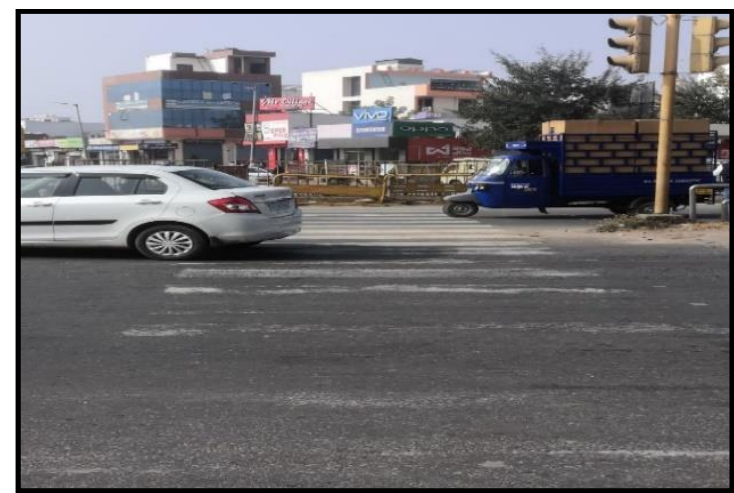

Fig. 2 Zebra Crossing Thermoplastic Paint Worn Out and Rutting/Raveling at Crossings

The existing position of Bhrigu Path junction is given in Fig 3. 


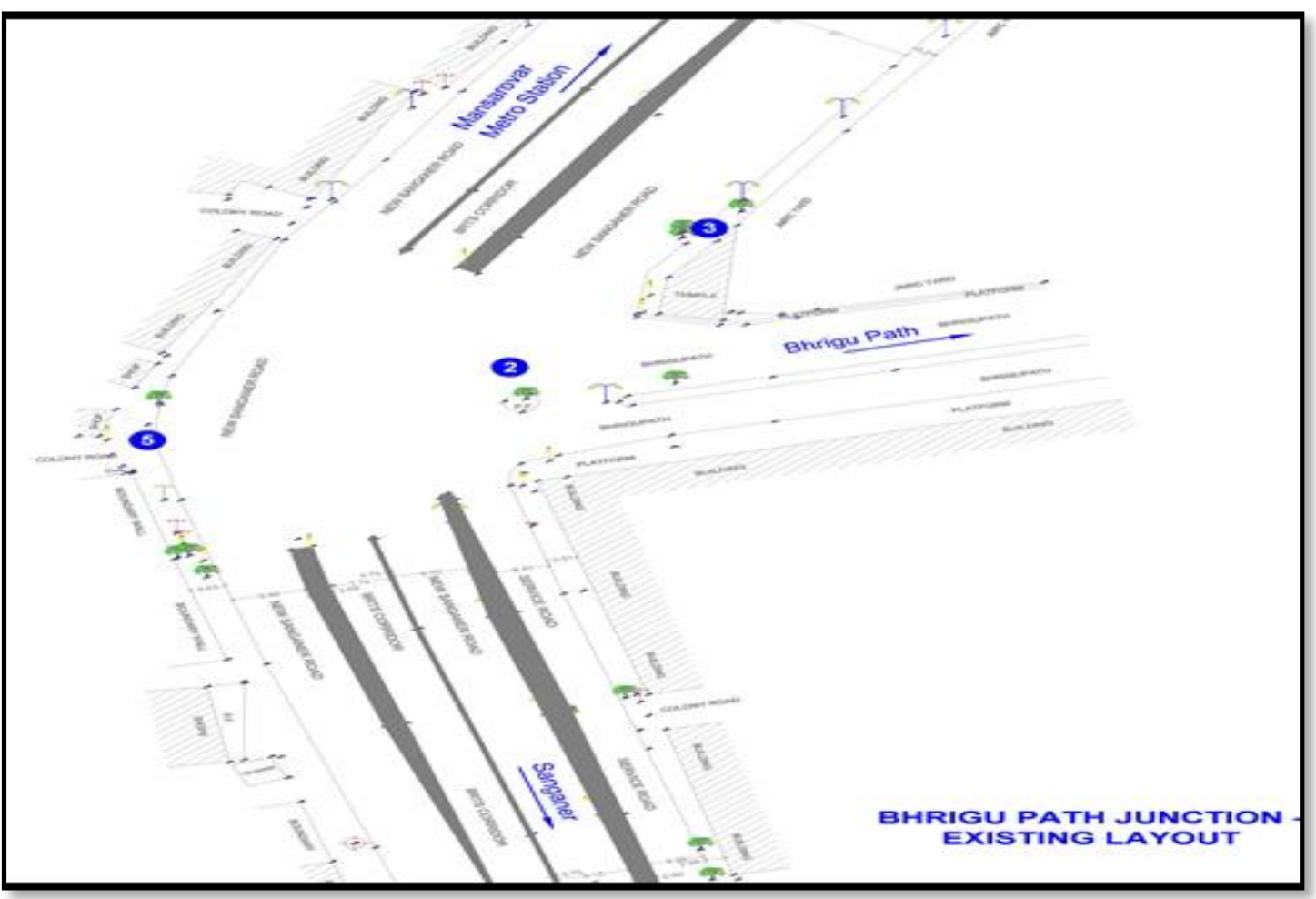

Fig. 3 Existing Layout of Bhrigu Path Junction

\section{RESULTS AND ANALYSIS}

After the detailed study of the existing junction at Bhrigu Path, the suggested safety gains by redesigning the junction are:

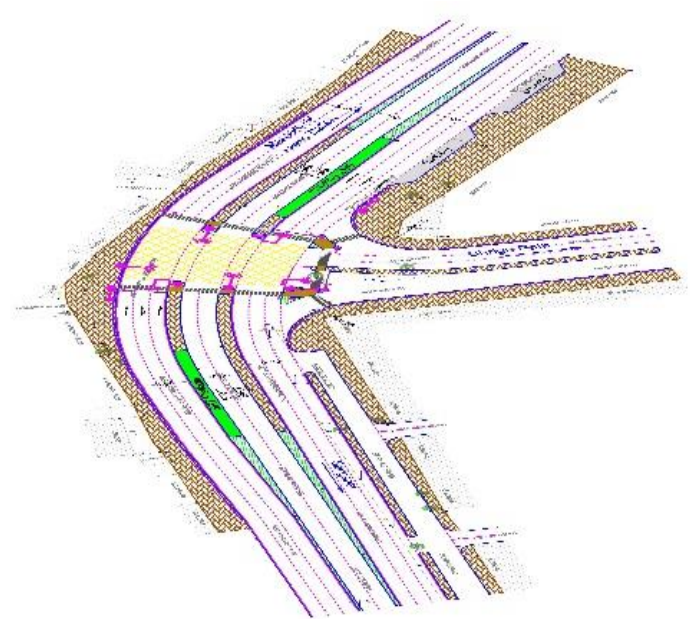

Fig. 4 Revised Proposed Design of Junction Safety Gains by Redesign

- Provided refuge islands between carriageway and BRT lane, as they are essential when pedestrians need to cross more than two lanes. Wide islands give time for pedestrian to take refuge and reorient them before crossing the rest of the street. The refuge should be of the same width as the pedestrian crossing and the width should not be less than $2 \mathrm{~m}$, enough to park a wheelchair (as per IRC:103-2012, 6.7.3.3).

- It is recommended to provide user-friendly channelizing islands for pedestrian safety and also for streamlining the vehicular movements in junction area, and all these are provided within available ROW. The table-top speed breaker arrangement at free-left lanes lane for speed calming.

- Provided marked parallel parking bays along the road wherever possible to discourage unregulated and haphazard on-street parking. Footpath has been provided all along the junction influence area. Traffic lane width of $3.3 \mathrm{~m}$ will enhance the safety of vehicles in urban street.

- Replacement of Fixed Time traffic control signals/Flashing Amber with vehicle actuated signals to improve the safety as well as capacity of the junction during odd (off-peak) hours. Traffic signals are provided with primary, secondary, cantilever signal heads to be visible enough to be seen by all drivers and provided with pedestrian phases in the signal.

- It is recommended to provide Yellow Box marking in junction turning areas. One must not enter the box until exit road or lane is clear to avoid queuing within the boxed area.

- The side road has been brought nearly perpendicular to enhance the visibility of approaching side road traffic. This is done with no extra ROW.

The proposed layout with suggested improvements is shown in Fig 4. 


\section{CONCLUSION}

Safety design of intersections is of prime importance. The deficiency in the design were observed and the measures for improvements were suggested. The study suggests that without major demolition of the existing infrastructure, the improvement measures may be implemented on site.

\section{REFERENCES}

[1] Pandey, A. (2014). Human rights in relation to water in India. IOSR Journal of Humanities and Social Science, 19, 54-56.

[2] Ponnaluri, R. V. (2011). Sustainable Bus Rapid Transit initiatives in India: The role of decisive leadership and strong institutions. Transport Policy, 18(1), 269-275.
[3] Kathuria, A., Parida, M., Ravi Sekhar, C., \& Sharma, A. (2016). A review of bus rapid transit implementation in India. Cogent Engineering, 3(1), 1241168.

[4] Sidloski, M., \& Diab, E. (2020). Understanding the Effectiveness of Bus Rapid Transit Systems in Small and Medium-Sized Cities in North America. Transportation Research Record, 2674(10), 831-845.

[5] Patel, V., Bhagwat, K., \& Patel, D. (2020). A Comparative Study of Bus Rapid Transit System (BRTS) and Metro Rail as an urban mode of Transport. Psychology and Education Journal, 57(9), 4468-4479.

[6] Hossain, M. (2006). The issues and realities of BRT planning initiatives in developing Asian cities. Journal of Public Transportation, 9(3), 4

[7] Traffic \& Transportation Policies and Strategies in Urban Areas in India, Ministry of Urban Development INDIA. 